\title{
Pengembangan Sistem Hidroponik Otomatis-Modern Berbasis Panel Surya dan Baterai
}

\section{(Development of Modern Automatic Hydroponic Systems Based on Solar Panels and Batteries)}

\author{
Luthfansyah Mohammad ${ }^{1}$, Suyanto ${ }^{2}$, Muhammad Khamim Asy'ari ${ }^{3}$, Asma'ul Husna $^{4}$, Sarinah Pakpahan ${ }^{5}$
}

\begin{abstract}
The flexibility and the easiness of farming using modern hydroponic method have increased the installation requirements. The various types of plants can be applied to modern hydroponic systems, so this method has potential to be applied in various regions. However, not all regions have access to electricity networks. In fact, to operate modern hydroponic systems, an adequate supply of electrical power is required. In addition, a proper design becomes crucial part which has function to maintain the quality of inorganic substances as needed, accurately and automatically measured. Moreover, the system could be set in off-grid mode. Therefore, a further research of automatic hydroponics was conducted to solve various problems. The experimental data shows that the system is working accurately. The percentage of error sensor is not more than $10.75 \%$ and the accuracy of actuator performance is $100 \%$. The system is also capable of working for a full day through a solar panel system of $100 \mathrm{WP}$ and a battery of $27 \mathrm{Ah}$. In conclusion, the design of the automatic hydroponic system is capable of selfmaintaining nutritional and $\mathrm{pH}$ value, solving artificial irradiation time problem, while simultaneously operating in various areas in a portable manner.
\end{abstract}

Intisari-Fleksibilitas dan kemudahan bercocok tanam dengan metode hidroponik modern mengakibatkan kebutuhan pemasangan turut meningkat. Berbagai jenis tanaman dapat diterapkan pada sistem hidroponik modern, menyebabkan metode ini berpotensi untuk diaplikasikan di berbagai wilayah. Namun, tidak semua wilayah memiliki akses pada jaringan tenaga listrik, padahal sistem hidroponik modern membutuhkan suplai daya listrik yang cukup agar dapat beroperasi. Sistem hidroponik modern juga dituntut memiliki rancang-bangun yang berfungsi menjaga kualitas zat anorganik sesuai kebutuhan secara akurat dan terukur secara otomatis. Sistem yang dibuat juga didesain sehingga dapat beroperasi secara off-grid. Oleh karena itu, dilakukan sebuah pengembangan sistem hidroponik otomatis untuk menyelesaikan berbagai permasalahan. Data uji menunjukkan bahwa sistem telah bekerja dengan akurat. Error sensor tidak lebih dari $\mathbf{1 0 , 7 5 \%}$ dan akurasi kinerja aktuator sebesar $100 \%$. Sistem juga mampu bekerja selama satu hari penuh melalui sistem panel surya sebesar $100 \mathrm{WP}$ dan baterai berkapasitas $27 \mathrm{Ah}$. Sebagai kesimpulan, rancang bangun sistem hidroponik otomatis mampu melakukan self-maintenance terhadap nilai nutrisi dan $\mathrm{pH}$, memenuhi kebutuhan penyinaran

\footnotetext{
${ }^{1}$ Institut Teknologi Sepuluh Nopember, Kampus ITS Sukolilo 60111 INDONESIA (tlp: 085748832970; e-mail: luthfan48@gmail.com)

2,3,4,5 Departemen Teknik Fisika, Institut Teknologi Sepuluh Nopember, Kampus ITS Sukolilo 60111 INDONESIA (telp: 081233182898; e-mail: Suyanto@ep.its.ac.id)
}

buatan, sekaligus dapat beroperasi di berbagai area secara portabel.

Kata Kunci - Baterai, Hidroponik Otomatis, Kontrol PPM, Nilai pH, Penyinaran Buatan, Panel Surya.

\section{Pendahuluan}

Bioteknologi adalah salah satu bidang keilmuan yang fokus pada pemanfaatan prinsip-prinsip ilmiah dengan cara melakukan pemberdayaan makhluk hidup guna menghasilkan suatu konsep relasi yang konstruktif dan mutual. Hidroponik adalah salah satu contoh pengembangan bioteknologi yang dapat berperan dalam peningkatan produksi vegetasi atau pertanian. Hidroponik merupakan sistem hasil modifikasi pertanian modern berupa budidaya tanaman dengan tools berupa seperti media air dan dengan media cocok tanam yang memiliki porus.

Tanaman yang umum ditanam menggunakan hidroponik adalah sayur-sayuran, buah-buahan, maupun tanaman hias. Pada umumnya, sistem hidroponik memiliki media tanam berupa pipa atau wadah panjang berisi banyak tanaman sekaligus yang dialiri air secara terus menerus. Melihat arsitektur sistem hidroponik, tanaman yang sedang dibudidayakan dapat memperoleh nutrisi atau makanan dari larutan zat anorganik yang dialirkan bersama air melalui pipa atau dengan cara disiramkan. Terdapat banyak manfaat yang dapat diperoleh dari hidroponik, salah satunya adalah potensi produksi yang lebih terjamin dengan syarat lingkungan yang selalu terkontrol.

Hidroponik memerlukan perawatan yang berbeda dengan tanaman yang menggunakan media tanam pada umumnya. Untuk tetap tumbuh, hidroponik memerlukan udara, air, dan unsur hara pada tingkat tertentu yang secara umum diserap dari media tanamnya. Hal tersebut membuat pengondisian kualitas lingkungan sangat memengaruhi pertumbuhan hidroponik. Terdapat beberapa hal yang sangat dibutuhkan untuk menjaga kualitas lingkungan sesuai dengan kebutuhan tanaman hidroponik, di antaranya adalah suhu, kelembapan, air, kondisi $\mathrm{PH}$, nutrisi, dan cahaya. Kekurangan zat yang dibutuhkan akan membuat pertumbuhan tanaman hidroponik menjadi buruk Hal tersebut selanjutnya akan berdampak pada bentuk, rasa, hingga kandungan dari tanaman hidroponik.

Fleksibilitas dan kemudahan metode bercocok tanam hidroponik membuat kebutuhan pemasangan sistem di berbagai kondisi area turut meningkat. Variasi tanaman yang dapat diterapkan pada sistem hidroponik juga membuat metode 
ini potensial untuk dilakukan di berbagai area, seperti pegunungan, bangunan lepas pantai, gurun, maupun area yang terisolasi. Sayangnya, beberapa area pemasangan hidroponik tersebut tidak memiliki akses pada jaringan tenaga listrik, padahal agar sistem dapat beroperasi diperlukan suplai daya listrik yang mencukupi.

Berangkat dari permasalahan yang terjadi, dibuatlah suatu rancang-bangun sistem hidroponik otomatis yang dapat berfungsi menjaga kualitas zat anorganik sesuai kebutuhan secara akurat dan terukur. Sistem yang dibuat juga didesain agar dapat beroperasi secara off-grid atau tidak bergantung pada jaringan tenaga listrik. Oleh karena itu, beberapa pengujian dilakukan untuk melihat tingkat kinerja sistem. Data uji menunjukkan bahwa sistem telah bekerja dengan akurat sesuai dengan setting point dan batas toleransi error. Seluruh sensor yang digunakan memiliki error tidak lebih dari 10,75\%, dengan kondisi aktuator yang telah bekerja sesuai dengan desain. Panel surya mampu memproduksi rerata daya harian hingga $140 \mathrm{~W}$ dibantu dengan baterai sebagai penyimpan daya listrik yang dibutuhkan. Pada data akhir penelitian, sistem rancang bangun hidroponik otomatis telah mampu melakukan self-maintenance terhadap nilai nutrisi, tingkat $\mathrm{pH}$, serta kebutuhan penyinaran hidroponik. Sistem rancang bangun juga dapat beroperasi di berbagai area secara portable dengan sumber energi yang tercukupi dan baterai yang terisi penuh.

\section{Metodologi}

\section{A. Kultur Hidroponik}

Kultur hidroponik merupakan metode penanaman tanaman tanpa menggunakan media tumbuh dari tanah [1]. Hidroponik berarti penanaman dalam air yang mengandung campuran hara. Hidroponik dalam praktiknya tidak terlepas dari penggunaan media tumbuh lain yang bukan tanah sebagai penopang pertumbuhan tanaman.

Sistem hidroponik merupakan cara produksi tanaman yang sangat efektif. Sistem ini dikembangkan berdasarkan alasan bahwa jika tanaman diberi kondisi pertumbuhan yang optimal, potensi maksimum untuk berproduksi dapat tercapai. Hal ini berhubungan dengan pertumbuhan sistem perakaran tanaman. Pertumbuhan perakaran tanaman yang optimum akan menghasilkan pertumbuhan tunas atau bagian atas yang sangat tinggi. Larutan nutrisi yang diberikan pada sistem hidroponik mengandung komposisi garam-garam organik yang berimbang untuk menumbuhkan perakaran dengan kondisi lingkungan perakaran yang ideal [2].

Sistem hidroponik memiliki beberapa kelebihan dan kekurangan jika dibandingkan dengan pertanian konvensional. Kelebihan sistem hidroponik antara lain penggunaan lahan lebih efisien; tanaman berproduksi tanpa menggunakan tanah; tidak ada risiko untuk penanaman terus-menerus sepanjang tahun; kuantitas dan kualitas produksi lebih tinggi dan lebih bersih; penggunaan pupuk dan air yang lebih efisien; periode tanam lebih pendek; serta pengendalian hama dan penyakit yang lebih mudah. Sementara itu, kekurangan hidroponik antara lain membutuhkan modal yaitu sistem tertutup (nutrisi disirkulasi); jika ada tanaman yang terserang patogen, dalam waktu yang sangat singkat seluruh tanaman akan terkena serangan tersebut; pada kultur substrat, kapasitas memegang air media substrat lebih kecil daripada media tanah; sedangkan pada kultur air, volume air dan jumlah nutrisi sangat terbatas sehingga akan menyebabkan pelayuan tanaman yang cepat dan stres yang serius [3].

\section{B. Prinsip-Prinsip Teknik Hidroponik}

Sistem hidroponik pada dasarnya merupakan modifikasi dari sistem pengelolaan budidaya tanaman di lapangan secara lebih intensif untuk meningkatkan kuantitas dan kualitas produksi tanaman serta menjamin kontinuitas produksi tanaman. Beberapa aspek penting dalam pengelolaan tanaman dengan sistem hidroponik yang perlu diperhatikan yaitu unsur-unsur penting, formula nutrisi dan cara aplikasinya, serta kepekatan larutan nutrisi dan $\mathrm{pH}$ larutan.

1) Unsur-Unsur Penting: Tanaman membutuhkan enam belas unsur hara/nutrisi untuk pertumbuhan yang berasal dari udara, air, dan pupuk. Unsur-unsur tersebut adalah karbon (C), hidrogen $(\mathrm{H})$, oksigen $(\mathrm{O})$, nitrogen $(\mathrm{N})$, fosfor $(\mathrm{P})$, kalium $(\mathrm{K})$, sulfur $(\mathrm{S})$, kalsium $(\mathrm{Ca})$, besi $(\mathrm{Fe})$, magnesium $(\mathrm{Mg})$, boron $(\mathrm{B})$, mangan $(\mathrm{Mn})$, tembaga $(\mathrm{Cu})$, seng $(\mathrm{Zn})$, molibdenum (Mo), dan klorin $(\mathrm{Cl})$. Unsur-unsur $\mathrm{C}, \mathrm{H}$, dan $\mathrm{O}$ biasanya disuplai dari udara dan air dalam jumlah yang cukup. Unsur hara lainnya didapatkan melalui pemupukan atau larutan nutrisi [1].

Unsur-unsur nutrisi penting dapat digolongkan ke dalam tiga kelompok berdasarkan kecepatan hilangnya dari larutan [4]. Kelompok pertama adalah unsur-unsur yang secara aktif diserap oleh akar dan hilang dari larutan dalam beberapa jam, yaitu N, P, K, dan Mn. Kelompok kedua adalah unsur-unsur yang mempunyai tingkat serapan sedang dan biasanya hilang dari larutan agak lebih cepat daripada air yang hilang $(\mathrm{Mg}, \mathrm{S}$, $\mathrm{Fe}, \mathrm{Zn}, \mathrm{Cu}, \mathrm{Mo}, \mathrm{Cl}$ ). Kelompok ketiga adalah unsur-unsur yang secara pasif diserap dari larutan dan sering bertumpuk dalam larutan (Ca dan B).

$\mathrm{N}, \mathrm{P}, \mathrm{K}$, dan Mn harus tetap dijaga pada konsentrasi rendah dalam larutan untuk mencegah akumulasi yang bersifat racun bagi tanaman. Konsentrasi yang tinggi dalam larutan dapat menyebabkan serapan yang berlebihan, yang dapat mengakibatkan ketidakseimbangan hara. Unsur N mempunyai pengaruh yang paling besar terhadap pertumbuhan, hasil, dan kualitas tanaman sayuran [5]. N untuk larutan hidroponik disuplai dalam bentuk nitrat. $\mathrm{N}$ dalam bentuk amonium nitrat mengurangi serapan $\mathrm{K}, \mathrm{Ca}, \mathrm{Mg}$, dan unsur mikro. Kandungan amonium nitrat harus di bawah $10 \%$ dari total kandungan $\mathrm{N}$ pada larutan nutrisi untuk mempertahankan keseimbangan pertumbuhan dan menghindari penyakit fisiologi yang berhubungan dengan keracunan amonia. Konsentrasi $\mathrm{P}$ yang tinggi menimbulkan defisiensi Fe dan Zn, sedangkan $\mathrm{K}$ yang tinggi dapat mengganggu serapan $\mathrm{Ca}$ dan $\mathrm{Mg}$ [6].

Unsur mikro dibutuhkan dalam jumlah kecil sebagai nutrisi untuk pertumbuhan dan perkembangan tanaman. Selain itu, unsur mikro juga penting untuk meningkatkan ketahanan tanaman terhadap serangan penyakit atau hama. Kekurangan Mn menyebabkan tanaman mudah terinfeksi oleh cendawan Pythium [4]. Cu dan Zn dapat menekan pertumbuhan mikrobia, tetapi pada konsentrasi agak tinggi menjadi racun bagi tanaman. Silikon juga bermanfaat untuk ketahanan tanaman, meskipun 


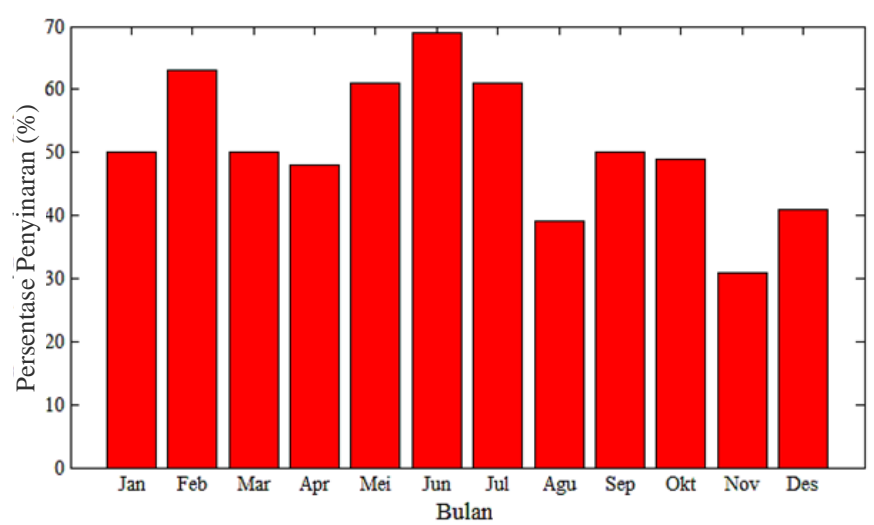

Gbr. 1 Data rata-rata penyinaran matahari setiap bulan.

tidak dikenal sebagai unsur esensial, yaitu dapat melindungi dari serangan hama dan penyakit [7], [8] dan melindungi dari keracunan logam berat.

2) Formula Nutrisi dan Cara Aplikasinya: Suplai kebutuhan nutrisi untuk tanaman dalam sistem hidroponik sangat penting untuk diperhatikan. Dua faktor penting dalam formula larutan nutrisi, terutama jika larutan yang digunakan akan disirkulasi (closed system), adalah komposisi larutan dan konsentrasi larutan. Kedua faktor ini sangat menentukan produksi tanaman. Setiap jenis tanaman, bahkan antar varietas, membutuhkan keseimbangan jumlah dan komposisi larutan nutrisi yang berbeda [9]. Beberapa faktor penting dalam menentukan formula nutrisi hidroponik adalah garam yang mudah larut dalam air, kandungan natrium, klorida, amonium dan nitrogen organik, atau unsur-unsur yang tidak dibutuhkan untuk pertumbuhan tanaman harus diminimalkan, digunakan komposisi bahan yang bersifat tidak antagonis satu dengan yang lainnya, serta dipilih yang ekonomis.

Aplikasi larutan nutrisi pada kultur hidroponik secara prinsip juga tergantung pada metode yang akan diterapkan. Beberapa metode tersebut antara lain adalah metode kultur pot dan kultur bedeng dengan sistem Nutrient Film Technique (NFT). Sistem pemberian larutan nutrisi pada kultur pot atau polybag dapat dilakukan secara manual atau irigasi tetes (drip irrigation) dengan frekuensi 3-5 kali per hari, tergantung pada kebutuhan tanaman, macam media tumbuh, dan cuaca/kondisi lingkungan. Sistem irigasi tetes lebih mudah, menghemat tenaga dan waktu, tetapi memiliki kendala berupa saluran irigasi yang sering tersumbat sehingga aliran nutrisi terhambat. Sementara itu, sistem pemberian larutan nutrisi pada kultur bedeng dengan sistem NFT dilakukan melalui perputaran aliran larutan nutrisi yang dibantu oleh pompa mesin atau dapat pula menggunakan cara yang lebih sederhana (tanpa pompa), yaitu menggunakan gaya gravitasi.

3) Kepekatan Larutan Nutrisi dan pH Larutan: Kepekatan larutan nutrisi hidroponik perlu diukur sehingga kebutuhan nutrisi dalam fase pertumbuhan tanaman dapat terpenuhi. Satuan untuk mengukur kepekatan suatu larutan cair atau nutrisi tanaman hidroponik yaitu Part per Million (PPM). Penambahan atau peningkatan PPM nutrisi disesuaikan dengan

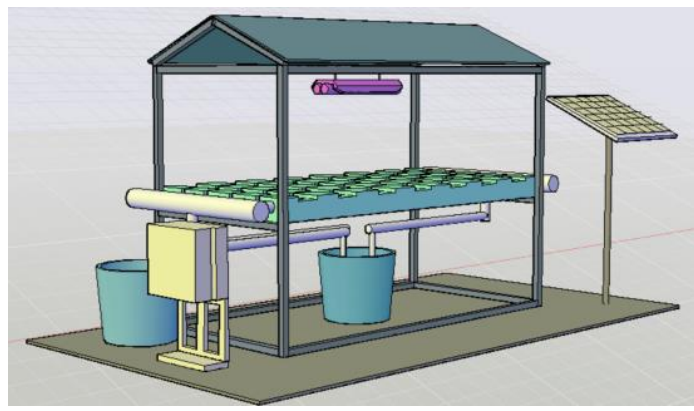

(a)

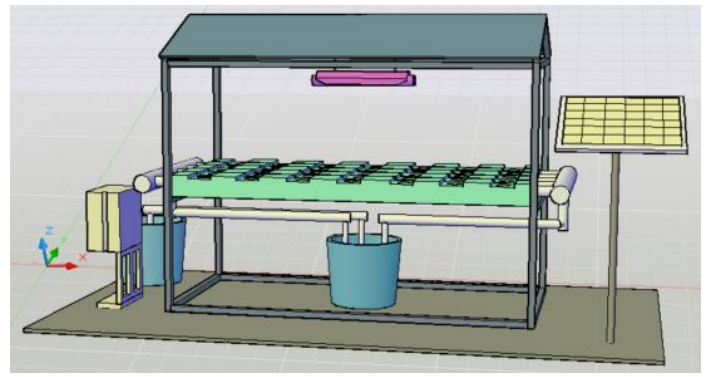

(b)

Gbr. 2 Desain konstruksi hidroponik otomatis berbasis panel surya, (a) tampak samping, (b) tampak depan.

umur dan jenis tanaman. Kepekatan nutrisi hidroponik diukur dengan sebuah alat yang disebut Total Dissolved Solid (TDS) meter dengan satuan PPM.

Faktor lain yang penting untuk dikontrol dalam sistem hidroponik adalah tingkat keasaman larutan atau $\mathrm{pH}$. Formula nutrisi yang berbeda mempunyai $\mathrm{pH}$ yang berbeda karena garam-garam pupuk mempunyai tingkat keasaman yang berbeda jika dilarutkan dalam air. Nilai $\mathrm{pH}$ larutan yang direkomendasikan untuk tanaman sayuran pada kultur hidroponik adalah antara 5,5 sampai 6,5, sehingga didapatkan hasil yang baik [10]. Ketersediaan $\mathrm{Mn}, \mathrm{Cu}, \mathrm{Zn}$, dan $\mathrm{Fe}$ berkurang pada $\mathrm{pH}$ yang lebih tinggi dan sedikit ada penurunan untuk ketersediaan $\mathrm{P}, \mathrm{K}, \mathrm{Ca}$, dan $\mathrm{Mg}$ pada $\mathrm{pH}$ yang lebih rendah. Penurunan ketersediaan nutrisi berarti penurunan serapan nutrisi oleh tanaman.

\section{Panel Surya}

Sel surya merupakan suatu perangkat energi baru terbarukan yang bertujuan untuk mengonversi sinar matahari menjadi energi listrik dengan menggunakan prinsip fotovoltaik. Gabungan beberapa sel surya disebut sebagai panel surya atau modul surya [11]. Perhitungan besarnya kapasitas modul surya yang digunakan pada sistem hidroponik dapat dilakukan dengan mempertimbangkan beberapa faktor, di antaranya jumlah total kebutuhan energi pada sistem, insolasi matahari, dan faktor penyesuaian. Besarnya kapasitas modul surya dapat dihitung menggunakan (1) [12].

Kapasitas Panel Surya $=\frac{\text { Total Kebutuhan Energi }}{\text { Insolasi Matahari }} \times$ Faktor Penyesuaian

Durasi penyinaran matahari di Indonesia dalam satu hari diperkirakan 8 jam, sehingga besarnya insolasi dapat dihitung dengan cara mengalikan durasi penyinaran dengan persentase 


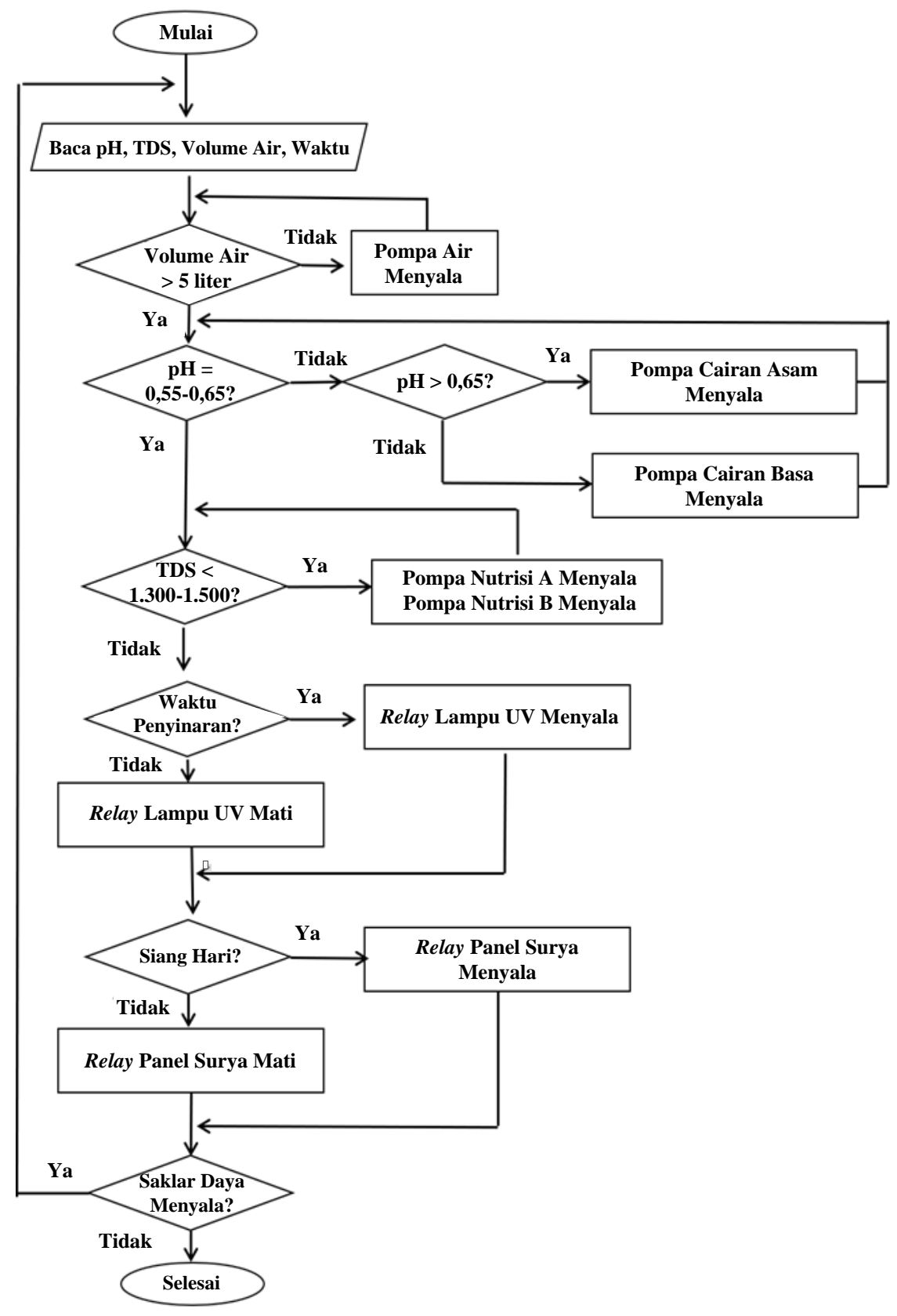

Gbr. 3 Diagram alir sistem kontrol.

penyinaran [13]. Persentase penyinaran matahari dalam setahun di Indonesia ditampilkan pada Gbr. 1.

\section{Baterai}

Baterai merupakan suatu perangkat yang mengandung sel listrik yang dapat menyimpan energi dan mengonversinya dalam bentuk daya. Proses elektrokimia yang terjadi di dalam baterai terdiri atas dua tahapan, yaitu tahap pengosongan dan tahap pengisian. Tahap pengosongan yaitu proses perubahan energi kimia menjadi energi listrik, sedangkan tahap pengisian yaitu proses pengubahan energi listrik menjadi energi kimia dengan cara melewatkan arus listrik dalam arah polaritas yang berlawanan di dalam sel [14]. Melihat hal tersebut, baterai cocok digunakan untuk menyimpan energi listrik yang dihasilkan dari panel surya selama siang hari [15]. Besarnya kapasitas baterai yang digunakan dalam suatu sistem tergantung pada besarnya energi beban total yang dibutuhkan oleh sistem tersebut. Besarnya kapasitas baterai yang dibutuhkan dapat dihitung dengan menggunakan (2).

$$
A h=\frac{E T}{V}
$$

$A h$ adalah kapasitas baterai, ET adalah energi total, dan $V$ adalah tegangan. Untuk mengetahui nilai keadaan pengisian baterai terhadap kapasitas, digunakan suatu metode yang bernama Coulomb counting dengan nilai pembacaan berupa State of Charge (SOC) dalam satuan persen [15]. Semakin besar nilai SOC, energi yang tersimpan di baterai semakin 


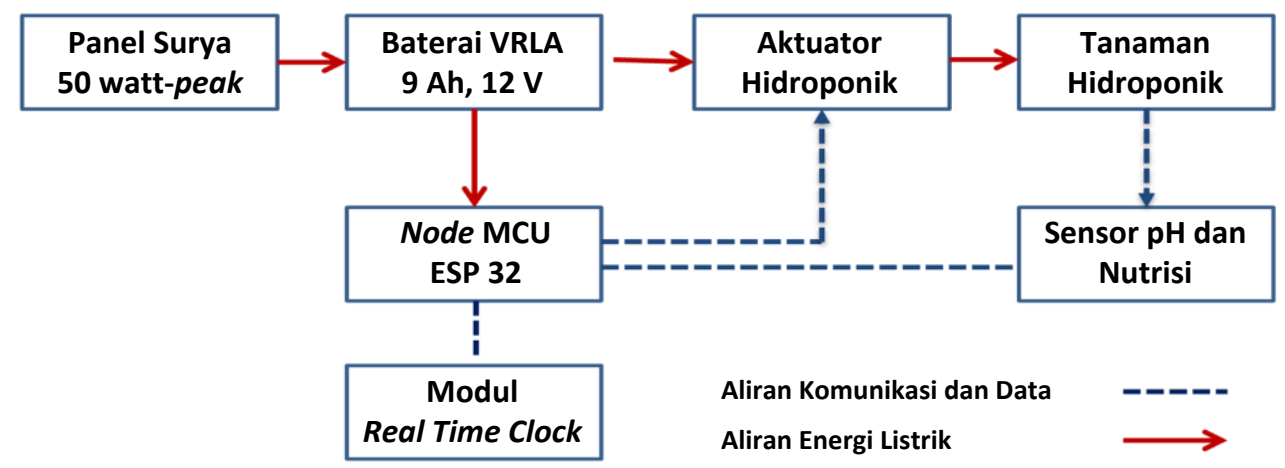

Gbr. 4 Diagram blok aliran daya listrik dan komunikasi.

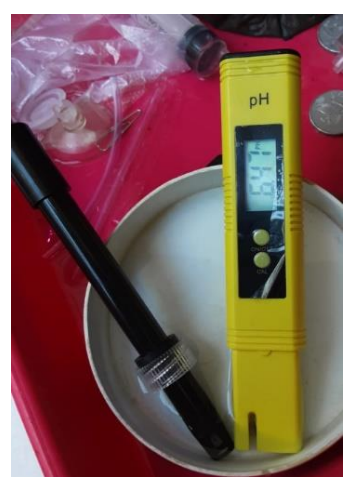

(a)

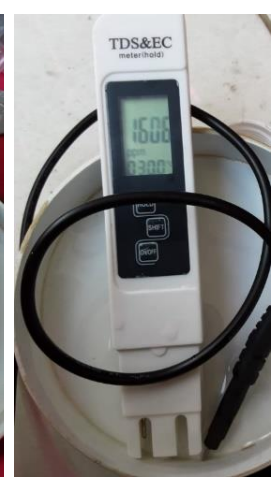

(b)
Gbr. 5 Alat ukur, (a) probe sensor $\mathrm{pH}$ dan $\mathrm{pH}$-meter, (b) probe sensor PPM dan PPM-meter

mendekati nilai penuh. Metode Coulomb counting ini mengukur besar arus dalam satuan coulomb yang berhasil masuk menuju atau keluar dari baterai.

\section{HASIL DAN PEMBAHASAN}

\section{A. Desain Sistem Keseluruhan}

Desain pemodelan tiga dimesi sistem secara keseluruhan ditunjukkan pada Gbr. 2. Panel surya berfungsi sebagai sumber penghasil energi kelistrikan sistem, baterai digunakan untuk menyimpan energi, sedangkan sensor dan aktuator digunakan untuk menjaga nilai setting point pada tanaman hidroponik.

Secara umum, metode kontrol yang digunakan dalam makalah ini tidak lepas dari arsitektur Multi Input Multi Output (MIMO). Terdapat beberapa variabel dependen yang membutuhkan multi sensor dan multi aktuator sebagai media kontrol. Dalam hal ini, konsep tersebut disederhakan melalui diagram alir yang ditunjukkan pada Gbr. 3. Proses diawali dengan menentukan terlebih dahulu nilai $\mathrm{pH}$, PPM, ketinggian air, dan kondisi waktu secara real-time. Selanjutnya sistem akan menyalakan pompa agar air mengalir menuju wadah utama. Air akan terus diukur ketinggiannya agar tidak melebihi ketinggian wadah utama. Jika air telah terisi sesuai setting point, selanjutnya sistem melakukan penyeimbangan kadar $\mathrm{pH}$ dalam wadah utama. Jika larutan pada wadah utama memiliki range di atas setting point, pompa akan mengalirkan larutan asam yang bertujuan untuk menurunkan tingkat basa. Hal tersebut juga berlaku ketika larutan terdeteksi berada di bawah setting point atau asam, pompa akan menyala dan mengalirkan larutan basa menuju wadah utama. Jika keadaan $\mathrm{pH}$ larutan telah berada pada batas toleransi setting point, selanjutnya sistem melakukan proses pada kondisi nutrisi atau PPM larutan wadah utama. Ketika nilai PPM berada di bawah setting point, pompa akan mengalirkan larutan nutrisi A dan nutrisi B ke dalam wadah utama. Selanjutnya sensor akan terus memantau kinerja berbagai variabel pengamatan agar sistem selalu berada pada kondisi setting point.

Untuk melakukan penghematan konsumsi energi listrik, pompa utama yang berfungsi menjalankan sirkulasi air dari wadah sistem menuju tanaman dan kembali lagi hanya akan beroperasi pada durasi waktu tertentu. Pompa beroperasi setiap 30 menit dan berhenti pada 30 menit berikutnya dalam satu hari. Selain itu, sistem penerangan juga tidak menyala secara terus menerus, tetapi hanya pada jam tertentu saja. Dalam makalah ini, sistem penerangan ultraviolet menyala selama 4 jam setiap hari, bergantung pada jenis tanaman yang ditanam. Secara keseluruhan, fungsi pewaktu pada sistem dibebankan pada modul Real Time Clock (RTC) agar sistem tetap beroperasi sesuai dengan jadwal yang telah ditentukan dengan akurat.

Gbr. 4 menunjukkan aliran daya dan kontrol yang bekerja pada sistem. Mulanya, energi listrik dihasilkan oleh panel surya $100 \mathrm{~W}$-peak, lalu energi listrik tersebut disimpan pada baterai 27Ah dengan tegangan terminal $12 \mathrm{~V}$. Setelah melalui beberapa rangkaian regulator tegangan, energi listrik tersebut dapat digunakan sebagai suplai daya mikrokontroler, sensor, dan aktuator.

\section{B. Kinerja Sensor}

Sensor yang digunakan dalam sistem hidroponik ini terdiri atas sensor PPM, sensor $\mathrm{pH}$, dan sensor volume air. Sensor PPM yang digunakan memiliki nomor seri SEN2044 Gravity Analog TDS Sensor Meter. Sensor $\mathrm{pH}$ yang digunakan adalah pH Sensor Module V.1.1 MSP340. Selanjutnya, sensor yang digunakan sebagai pengukur nilai volume atau ketinggian cairan pada wadah utama adalah water level sensor analog.

Sensor-sensor yang digunakan akan dikarakterisasi terlebih dahulu sebelum diintegrasikan dengan sistem kontrol pada sistem hidroponik. Karakterisasi digunakan untuk mengetahui nilai error dan akurasi masing-masing sensor. Perhitungan nilai error dilakukan dengan cara membandingkan dengan alat ukur yang telah terkalibrasi seperti pada Gbr. 5. 


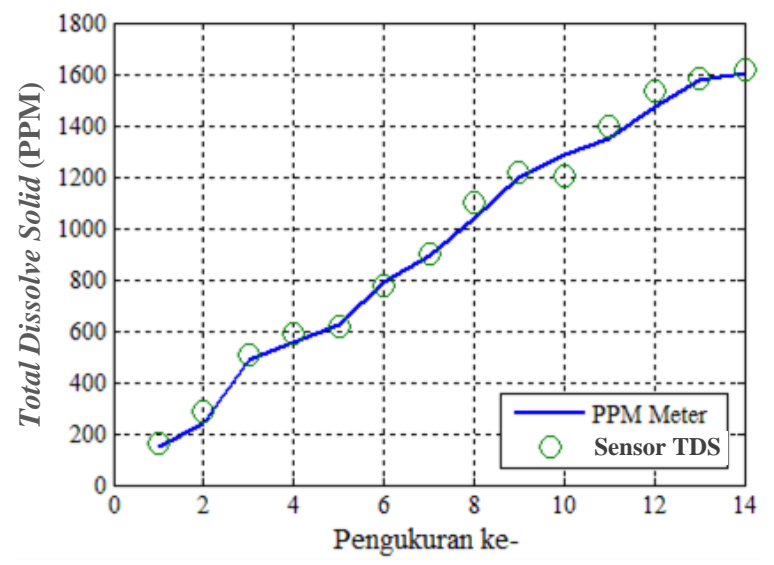

(a)

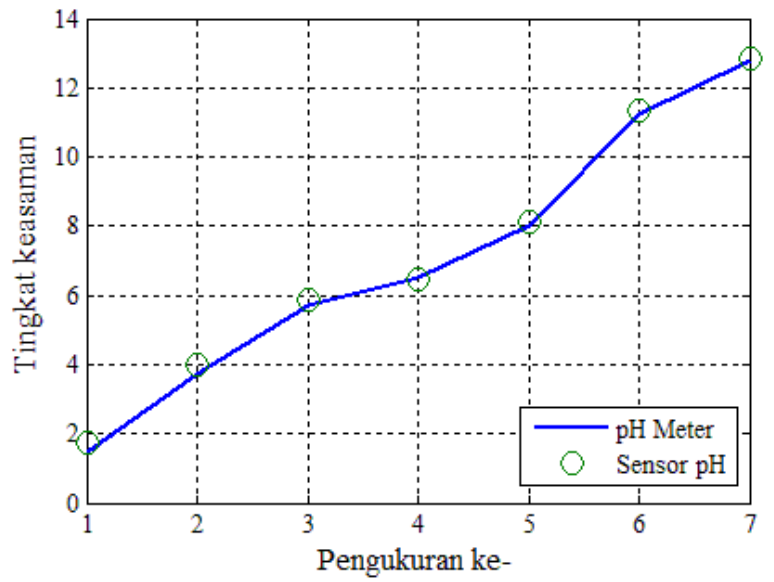

(b)

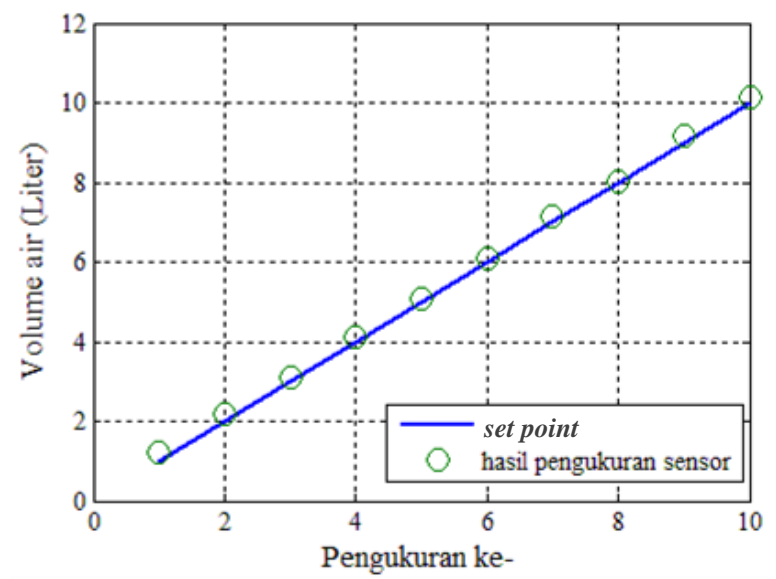

(c)

Gbr. 6 Grafik hasil karakterisasi sensor, (a) PPM, (b) pH, (c) volume air.

Perhitungan akurasi dilakukan dengan membandingkan sensor dengan alat ukur standar. Hasil dari masing-masing pengukuran pada sensor PPM, sensor $\mathrm{pH}$, dan sensor volume air ditampilkan pada Gbr. 6. Pada gambar tersebut, dapat dilihat bahwa error maksimal sebesar 81 PPM untuk sensor PPM, 0,29 untuk sensor $\mathrm{pH}$, dan 0,17 1 untuk sensor volume air. Akurasi sensor PPM sebesar 99,95\%, sensor pH sebesar 99,95\%, dan sensor volume air sebesar $99,96 \%$. Ketiga sensor yang

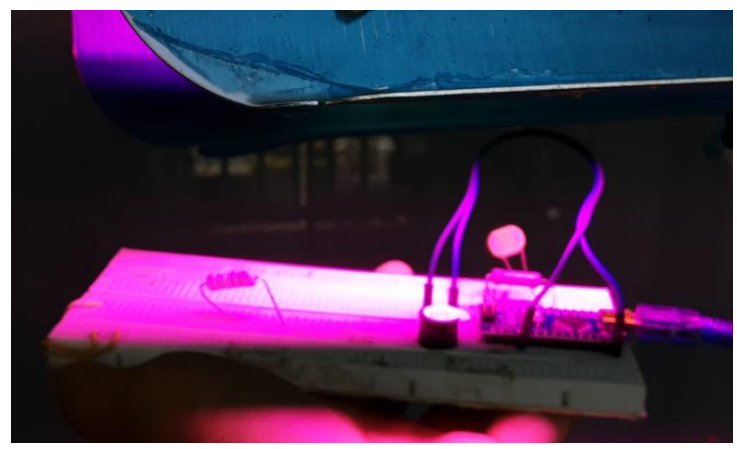

Gbr. 7 Pengujian sinar ultraviolet untuk penerangan buatan pada hidroponik.

digunakan mempunyai akurasi lebih dari 95\% sehingga dapat dilakukan tahapan selanjutnya, yaitu integrasi dengan sistem kontrol.

Error yang terjadi dapat diakibatkan oleh beberapa faktor. Salah satunya adalah munculnya sedimentasi atau penempelan material tertentu pada probe yang digunakan. Hal tersebut terjadi karena probe harus dicelupkan pada larutan agar nilai PPM atau pH dapat terbaca. Dengan tercelupnya probe pada larutan tersebut, konduktor transduser pada probe dapat tertutup oleh kerak akibat sedimentasi asam dan mineral.

\section{Penjadwalan Siklus Pompa dan Durasi Penyinaran}

Otomatisasi sistem pada hidroponik juga meliputi penggunaan lampu ultraviolet sebagai pengganti sinar matahari. Hal tersebut diupayakan agar sistem dapat bekerja dalam kondisi apa pun, khususnya pada daerah atau tempat yang minim penyinaran matahari. Selain itu, sistem juga dijadwalkan memiliki siklus operasi pompa yang disesuaikan dengan waktu. Hal tersebut digunakan untuk menghemat konsumsi daya listrik sistem dari baterai. Dari pengujian diketahui bahwa pompa telah bekerja sesuai dengan jadwal waktu yang telah ditentukan.

Pengujian lampu ultraviolet ditunjukkan pada Gbr. 7. Lampu ultraviolet yang digunakan telah beroperasi sesuai dengan durasi waktu yang telah ditentukan oleh modul RTC. Masingmasing aktuator dioperasikan menggunakan modul relay DC 5 $\mathrm{V}$ yang bersumber dari pembagi tegangan dari baterai. Pada makalah ini, pompa yang digunakan berjenis pompa DC submersible dengan daya rerata $10 \mathrm{~W}$ dan tegangan kerja $12 \mathrm{~V}$. Pompa jenis ini memiliki karakteristik pengoperasian yang harus berada di dalam air. Keunggulan pompa jenis submersible terletak pada konstruksi pompa yang tidak rusak atau mengalami short circuit ketika berada di dalam air.

\section{Desain dan Kinerja Sistem Panel Surya-Baterai}

Beban energi listrik yang digunakan dalam sistem hidroponik perlu dihitung untuk menentukan kapasistas panel surya dan baterai yang digunakan. Profil beban dan hasil perhitungan energi listrik untuk sistem hidroponik ditampilkan pada Tabel I.

Kapasitas panel surya yang dibutuhkan sebesar 73,3 Wp dan kapasitas baterai sebesar 22,9 Ah. Hasil tersebut didasarkan pada perhitungan menggunakan (1) tentang penentuan kapasitas panel surya dan (2) tentang penentuan kapasitas baterai. Hasil kalkulasi kapasitas panel surya dan baterai selanjutnya disesuaikan dengan nilai kapasitas yang umum 
TABEL I

PROFIL BEBAN DAN KALKULASI KONSUMSI ENERGI LISTRIK

\begin{tabular}{|l|c|r|r|r|}
\hline Jenis Beban & Jumlah & $\begin{array}{c}\text { Waktu } \\
\text { Operasional } \\
(\mathbf{h})\end{array}$ & \multicolumn{1}{c|}{$\begin{array}{c}\text { Daya } \\
\text { (W) }\end{array}$} & \multicolumn{1}{c|}{$\begin{array}{c}\text { Energi } \\
\text { (Wh) }\end{array}$} \\
\hline Sensor PPM & 1 & 0,05 & 4 & 0,2 \\
\hline Sensor pH & 1 & 0,05 & 4 & 0,2 \\
\hline Pompa valve & 4 & 0,05 & 4 & 0,8 \\
\hline Lampu UV & 1 & 4 & 25 & 100 \\
\hline Kontroller & 1 & 24 & 3 & 72 \\
\hline Pompa utama & 1 & 12 & 10 & 120 \\
\hline Total & \multicolumn{5}{|r|}{} \\
\hline
\end{tabular}

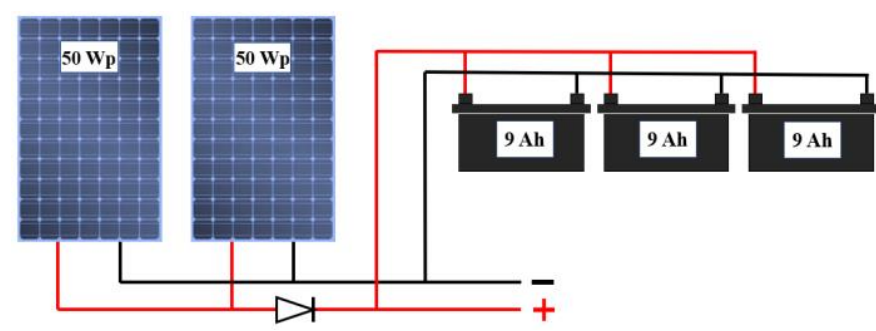

Gbr. 8 Skematik hubungan paralel panel surya dengan baterai penyimpanan. digunakan atau tersedia di pasar. Oleh karena itu, panel surya yang digunakan sebesar $100 \mathrm{Wp}$ dan kapasitas baterai sebesar $27 \mathrm{Ah}$.

Rangkaian menggunakan tiga buah baterai dengan kapasitas 9 Ah yang dikoneksi secara paralel. Skema rangkaian pada panel surya ditunjukkan pada Gbr. 8. Hal tersebut membuat baterai memiliki tegangan terminal sebesar $12 \mathrm{~V}$, dengan kapasitas baterai sebesar 27 Ah. Untuk menyesuaikan kebutuhan beban, selanjutnya dua buah panel surya dengan kapasitas $50 \mathrm{Wp}$ dihubungkan secara paralel agar tegangan kerja mendekati tegangan pengisian baterai. Sebagai pengaman tambahan, digunakan sebuah diode yang mampu melakukan blok arus, khususnya saat sistem berada di malam hari. Selain itu, untuk menjaga kondisi kesehatan baterai, ditambahkan sebuah modul Low Voltage Disconnect (LVD) yang mampu melakukan pemutusan koneksi ketika tegangan terminal baterai kurang dari $12 \mathrm{~V}$.

Gbr. 9(a) merupakan grafik yang menunjukkan rata-rata daya listrik yang diproduksi oleh panel surya terhadap waktu (jam) mulai pagi hingga sore hari. Grafik tersebut menunjukkan bahwa produksi daya listrik panel surya tertinggi terjadi pada pukul 12.00 dengan daya rerata sebesar $54 \mathrm{~W}$, dengan total energi maksimum yang dapat diproduksi dalam satu hari sebesar 316,69 Wh. Gbr. 9(b) menunjukkan grafik SOC pada baterai ketika melakukan pengisian selama 8 jam.

\section{E. Kinerja Keseluruhan Sistem}

Data yang dijadikan acuan (variabel proses kontrol) dari sistem kontrol hidroponik adalah nilai PPM dan pH. Pengujian total dilakukan dengan kondisi awal wadah utama yang kosong. Pengujian total panel surya dan baterai yang digunakan diperlihatkan pada Gbr. 10.

Selanjutnya sensor akan mengukur level air, kualitas PPM, dan level $\mathrm{pH}$. Terdapat empat buah aktuator yang bekerja untuk variabel PPM dan $\mathrm{pH}$. Aktuator tersebut berupa pompa valve yang berada di dalam dua buah botol nutrisi dan dua buah botol

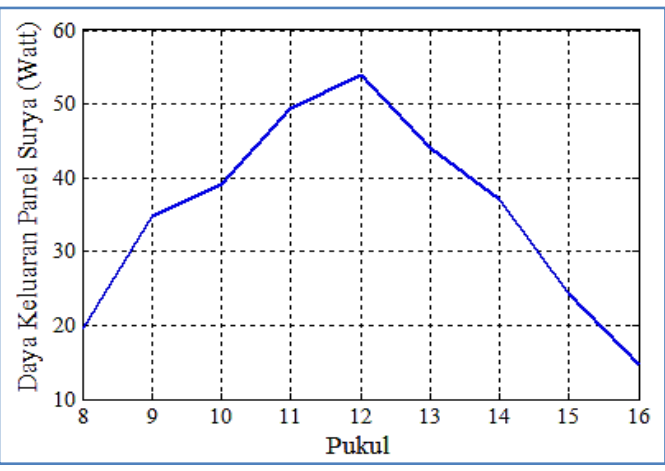

(a)

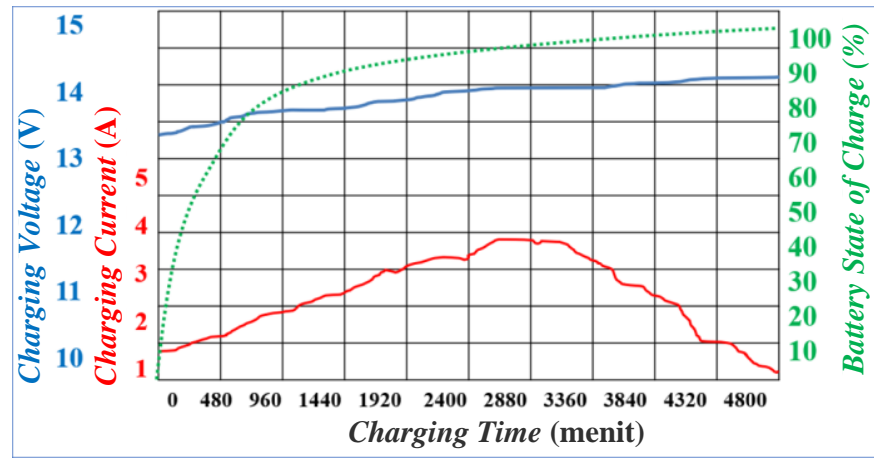

(b)

Gbr. 9 Hasil pengujian, (a) produksi daya panel surya, (b) grafik state of charge baterai.

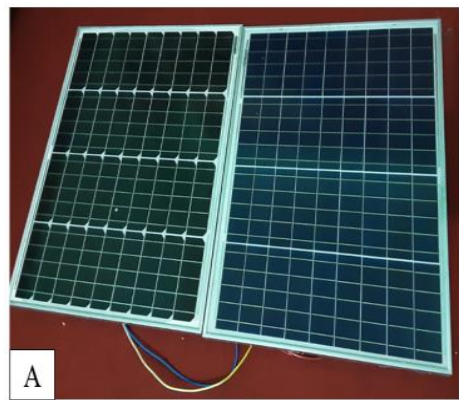

(a)

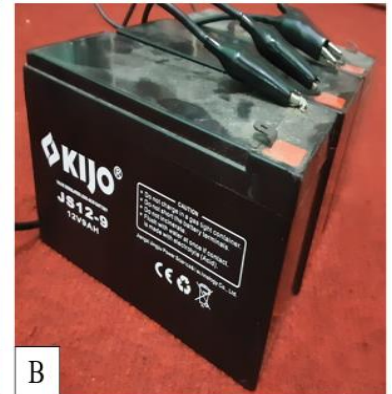

(b)
Gbr. 10 Sumber energi listrik sistem, (a) panel surya, (b) baterai.

$\mathrm{pH}$, seperti pada Gbr. 11. Setelah sensor mendapatkan masingmasing data yang dibutuhkan, aktuator bekerja dan didapatkan data seperti pada Tabel II. Pada proses pencampuran larutan, dibutuhkan setidaknya 3 menit agar larutan dapat tercampur dengan baik pada wadah utama. Selanjutnya, sistem akan bekerja kembali dengan mengukur nilai variabel dan aktuator akan beroperasi sesuai dengan hasil pembacaan. Pada rata-rata pengujian, setidaknya sistem membutuhkan waktu 15 menit untuk memperbaiki kualitas nutrisi dan menyeimbangkan nilai pH sesuai dengan setting point.

Mikrokontroler yang digunakan adalah Arduino nano. Relay modul delapan pin juga digunakan untuk melakukan switching aktuator. Sebagai tindakan preventif ketika baterai tidak terisi penuh, sistem juga dilengkapi dengan power supply DC $12 \mathrm{~V}$ yang dapat disambung dengan jaringan listrik AC $220 \mathrm{~V}$. 
TABEL II

HASIL SISTEM KONTROL PADA SISTEM HIDROPONIK

\begin{tabular}{|c|c|c|c|c|c|c|}
\hline \multirow{2}{*}{$\begin{array}{l}\text { Waktu } \\
\text { Respon } \\
\text { Sistem } \\
\text { (Menit) }\end{array}$} & \multicolumn{2}{|c|}{$\begin{array}{c}\text { Variabel } \\
\text { Proses } \\
\text { (Kontrol) } \\
\end{array}$} & \multicolumn{4}{|c|}{ Aktuator } \\
\hline & pH & $\begin{array}{c}\text { Nilai } \\
\text { Nutrisi } \\
\text { (PPM) } \\
\end{array}$ & Nutrisi A & Nutrisi B & pH $U p$ & $\begin{array}{c}\text { pH } \\
\text { Down }\end{array}$ \\
\hline 0 & 5,14 & 473 & ON & $\mathrm{ON}$ & $\mathrm{ON}$ & OFF \\
\hline 3 & 5,35 & 815 & $\mathrm{ON}$ & $\mathrm{ON}$ & OFF & $\mathrm{ON}$ \\
\hline 6 & 6,08 & 1.194 & $\mathrm{ON}$ & $\mathrm{ON}$ & OFF & ON \\
\hline 9 & 6,06 & 1.377 & $\mathrm{ON}$ & $\mathrm{ON}$ & $\mathrm{OFF}$ & OFF \\
\hline 12 & 6,05 & 1.582 & $\mathrm{ON}$ & $\mathrm{ON}$ & OFF & OFF \\
\hline 15 & 6,05 & 1.582 & $\mathrm{OFF}$ & OFF & OFF & OFF \\
\hline
\end{tabular}

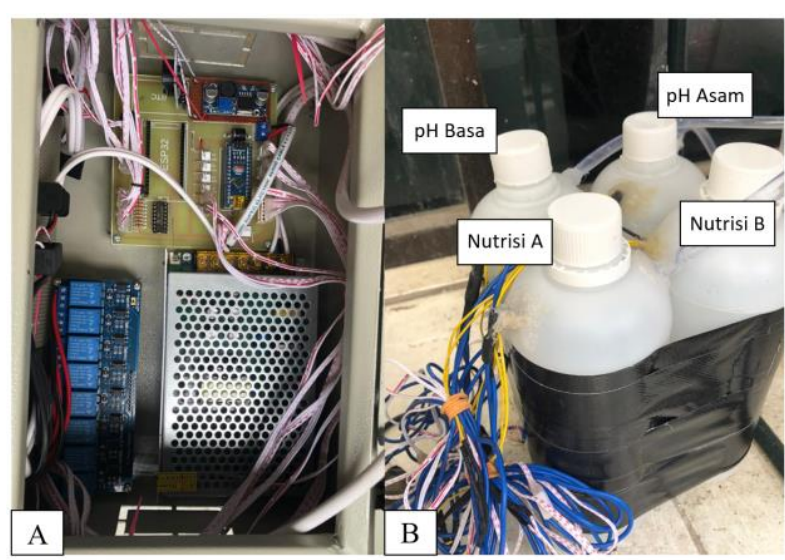

(a)

(b)

Gbr. 11 Hardware sistem, (a) mikrokontroler dan sistem kelistrikan di dalam kotak panel, (b) botol larutan yang akan dipompa ke wadah utama.

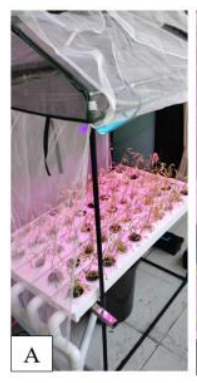

(a)

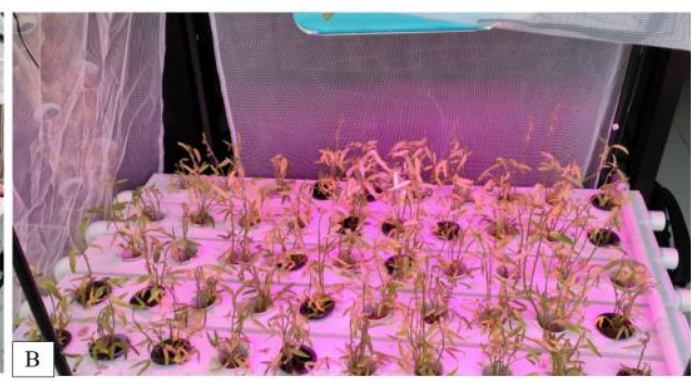

(b)
Gbr. 12 Sistem hidroponik otomatis, (a) sistem tampak samping, (b) tanaman pada pipa dan cahaya buatan.

Hasil akhir sistem hidroponik diperlihatkan pada Gbr. 12. Secara total, sistem yang dirancang telah bekerja sesuai dengan setting point dan seluruh sistem kelistrikan dapat beroperasi sesuai dengan fungsi yang ditentukan.

\section{KESIMPULAN}

Seluruh pengujian dilakukan guna mengetahui respons sistem terhadap setting point. Sistem yang diuji meliputi sensor, aktuator, dan modul referensi proses lainnya. Hasil pembacaan menunjukkan bahwa seluruh sensor yang digunakan memiliki error tidak lebih dari $10,75 \%$, dengan tingkat akurasi kerja aktuator yang mencapai $100 \%$. Siklus kerja pompa dan durasi penyinaran lampu ultraviolet juga dapat beroperasi sesuai dengan penjadwalan waktu yang dikehendaki. Pada sisi energi listrik, panel surya dapat menghasilkan keluaran daya listrik yang tidak kurang dari estimasi dan baterai mampu menyimpan energi sesuai dengan kebutuhan sistem selama satu hari. Sebagai kesimpulan akhir, sistem telah terbukti mampu menjaga nilai kualitas hidroponik sesuai dengan kebutuhan tanaman sekaligus mampu membuat hidroponik menjadi fleksibel dan dapat dipasang di berbagai area.

\section{REFERENSI}

[1] R. Rosliani dan S. Sumarni, Budidaya Tanaman Sayuran dengan Sistem Hidroponik, Bandung, Indonesia: Balai Penelitian Tanaman Sayuran, 2005.

[2] K. Raffar, "Hydroponics in Tropica," dipublikasikan pada International Seminar on Hydroponic Culture of High Value Crops in the Tropics, Malaysia, 25-27 Nov. 1990.

[3] D. Rosario, A. Dafrosa, dan P. Santos, "Hydroponic Culture of Crops in the Philippines: Problems and Prospect," dipublikasikan pada International Seminar on Hydroponic Culture of High Value Crops in the Tropics, Malaysia, 25-27 Nov. 1990.

[4] B. Bugbee, "Nutrient Management in Recirculating Hydroponic Culture," The South Pacific Soil-less Culture Conference, 2003. hal. 99-112.

[5] K.-Y. Kim, "Status and Prospect of Hydroponics Crop Production in Korea," dipublikasikan pada International Seminar on Hydroponic Culture of High Value Crops in the Tropics, Malaysia, 25-27 Nov. 1990.

[6] R.L. Chaney dan B.A. Coulombe, "Effect of Phosphate on Regulation of Fe-Stress in Soybean and Peanut," Journal of Plant Nutrition, Vol. 5, No. 4-7, hal. 469-487, 1982.

[7] M. Cherif, J. Menzies, D. Ehret, C. Boganoff, dan R. Belanger, "Yield of Cucumber Infected with Pythium Aphanidermatum when Grown with Soluble Silicon," Horticultural Science, Vol. 29, No. 8, hal. 896-897, 1994.

[8] M.D. Winslow, "Silicon, Disease Resistance and Yield of Rice Genotypes Under Upland Cultural Conditions," Crop Science, Vol. 32, No. 5, hal. 1208-1213, 1992.

[9] J. Valamis dan D. Williams, "Manganese and Silicon Interaction in the Gramineae," Plant and Soil, Vol. 27, pp. 131-140, 1967.

[10] M.E. Marvel, "Hydroponic Culture of Vegetable Crops," University of Florida, Gainesville, USA, 1974

[11] B.H. Purwoto, Jatmiko, M. Alimul F., dan I.F. Huda, "Efisiensi Penggunaan Panel Surya sebagai Sumber Energi Alternatif," Emitor: J. Tek. Elektro, Vol. 18, No. 1, hal. 10-14, 2018.

[12] M. Hankins, Stand-alone Solar Electric Systems: The Earthscan Expert Handbook for Planning, Design and Installation, $1^{\text {st }}$ ed., London, UK: Routledge. 2010.

[13] M. Syukri dan Suriadi, "Perencanaan Pembangkit Listrik Tenaga Surya (PLTS) Terpadu Menggunakan Software PVSYST pada Komplek Perumahan di Banda Aceh," Jurnal Rekayasa Elektrika, Vol. 9, No. 2, hal. 77-80, 2010.

[14] P.M. Hunter dan A.H. Anbuky, "VRLA Battery Virtual Reference Electrode: Battery Float Charge Analysis," Vol. 23, No. 3, hal. 879-886, 2008.

[15] L. Mohammad, E. Prasetyono, dan F.D. Murdianto, "Performance Evaluation of ACO-MPPT and Constant Voltage Method for Street Lighting Charging System," 2019 International Seminar on Application for Technology of Information and Communication (iSemantic), 2019, hal. 411-416. 